\title{
Three-level inverter configuration cascading two two-level inverters
}

\author{
V.T. Somasekhar and K. Gopakumar
}

\begin{abstract}
A power circuit configuration to realise three-level inversion is proposed. Three-level inversion is realised by connecting two two-level inverters in cascade, in the proposed configuration. An isolated DC power supply is used to supply each inverter in this power circuit. Each DC-link voltage is equal to half of the DC-link voltage in a conventional NPC (neutral point clamped) three-level inverter topology. Neutral point fluctuations are absent, and fast recovery neutral clamping diodes are not needed. The proposed inverter scheme produces 64 space-vector combinations distributed over 19 space-vector locations as compared to 27 combinations in a conventional three-level topology. The present power circuit can be operated as a two-level inverter in the range of lower modulation, by clamping one inverter to a zero state and by switching the other inverter. When compared to the H-bridge topology, this circuit needs one power supply less. A space vector based PWM scheme is used for the experimental verification of the proposed topology.
\end{abstract}

\section{Introduction}

Three-level inverters have been extensively researched ever since they were introduced by Nabae et al. [1]. The advantage of the three-level topology is that multilevel voltage waveforms can be synthesised using devices with lower voltage ratings. The neutral-clamped circuit topology suggested in [1], although simple and elegant, has some disadvantages. The DC-bus capacitors in this circuit configuration carry load currents causing a fluctuating neutral point. The H-bridge topology $[2,3]$ eliminates this problem, but requires three isolated power supplies and hence is an expensive proposition. A modification of the conventional neutral-clamped inverter has been suggested in [4], in which a capacitor is added across the neutral clamping diodes, to ensure a dynamic balancing of the DC-bus capacitors. However, this method does not eliminate the neutral-point fluctuations completely although it effectively reduces them. Two two-level inverters connected at either end of an open-end winding induction motor drive also achieve three-level inversion $[5,6]$. These schemes also require transformer isolation for the elimination of the harmonic currents of the triplen order in the phases. However, to implement these schemes, one needs to open the neutral point of the stator windings.

In this paper, an alternative circuit topology for threelevel inversion is proposed. In this circuit configuration, three-level inversion is achieved by connecting two two-level inverters in cascade. achieved by connecting two two-level inverters in cascade. From Fig. 1, it may be seen that the output phases of inverter-1 are connected to the DC-input points of the corresponding phases in inverter-2. Each inverter is operated with an isolated DC power supply, with a voltage of $V_{d c} / 2$ (Fig. 1). The output voltages of inverter-1 (the voltages of the individual phases $A_{1}, B_{1}$ and $C_{1}$ of inverter-1), with respect to the point $\mathrm{O}$, are denoted as $v_{A 1 O}, v_{B 1 O}$ and $v_{C 1 O}$ respectively (Fig. 1). The pole voltages of inverter-2 (the voltages of the individual phases $A_{2}, B_{2}$ and $C_{2}$ of inverter2 , with respect to the point $\mathrm{O}$ ) are denoted as $v_{A 2 O}, v_{B 2 O}$ and $v_{\mathrm{C} 2 \mathrm{O}}$ respectively.

The pole voltage of any phase for inverter- 2 attains a voltage of $V_{d c} / 2$, if

(a) the top switch of that leg in inverter-2 is turned on,

(b) the bottom switch of the corresponding leg in inverter-1 is turned on.

Similarly the pole voltage of any phase in inverter-2 attains a voltage of $V_{d c}$, if

(a) the top switch of that leg in inverter- 2 is turned on and

(b) the top switch of the corresponding leg in inverter-1 is turned on.

Thus, the DC-input points of individual phases of inverter-2 may be connected to a DC-link voltage of either $V_{d c}$ or $V_{d c} / 2$ by turning on the top switch or the bottom switch of the corresponding phase leg in inverter-1.

Additionally, the pole voltage of a given phase in inverter-2 attains a voltage of zero, if the bottom switch of the corresponding leg in inverter- 2 is turned on. In this case, the DC-input point of that phase for inverter- 2 is floating as the top and bottom switches are switched complementarily in any leg in a two-level inverter. Thus, the pole voltage of a given phase for inverter- 2 is capable of 


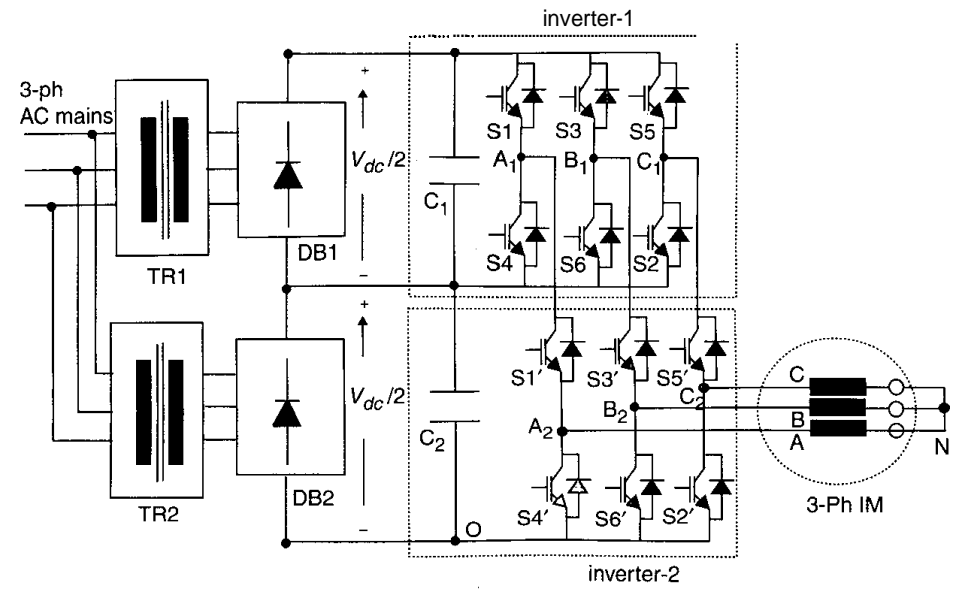

Fig. 1 The power circuit configuration of the proposed three-level inverter

assuming one of the three possible values $0, V_{d c} / 2$ and $V_{d c}$, which is the characteristic of a three-level inverter.

Table 1 depicts individual inverter states and the switches turned on to realise those states, for both the inverters.

An example is presented in the following paragraph to determine the resultant space-vector location for a spacevector combination of $5-7^{\prime}$ of the two inverters. The combination 5-7' implies that the switching state for inverter- 1 is $(--+)$ and that for inverter- 2 is $(+++)$. A ' + ' indicates that a top switch in an inverter leg is turned on and a '-' indicates that the bottom switch in an inverter leg is turned on. The space-vector $\boldsymbol{V}_{\boldsymbol{s}}$ constituted by the pole voltages $v_{A 2 O}, v_{B 2 O}$ and $v_{C 2 O}$ is defined as:

$$
\boldsymbol{V}_{\boldsymbol{s}}=v_{A 2 O}+v_{B 2 O} e^{j(2 \pi / 3)}+v_{C 2 O} e^{j(4 \pi / 3)}
$$

If inverter-1 assumes a state of $5(--+)$ and inverter-2 assumes a state of $7(+++)$, from the earlier discussion it follows that:

$$
v_{A 2 O}=V_{d c} / 2 ; v_{B 2 O}=V_{d c} / 2 ; v_{C 2 O}=V_{d c}
$$

Consequently, the space-vectorlocation for the above set of pole voltages is given by:

$$
\boldsymbol{V}_{s}=\left(V_{d c} / 2\right)+\left(V_{d c} / 2\right) e^{j(2 \pi / 3)}+\left(V_{d c}\right) e^{j(4 \pi / 3)}
$$

It may be verified that the tip of the space-vector corresponding to the above pole voltages is located at the point E in Fig. 2. The space-vector locations corresponding to the rest of the 63 combinations may similarly be

\begin{tabular}{|c|c|c|c|}
\hline $\begin{array}{l}\text { State of } \\
\text { inverter-1 }\end{array}$ & $\begin{array}{l}\text { Switches } \\
\text { turned on }\end{array}$ & $\begin{array}{l}\text { State of } \\
\text { inverter-2 }\end{array}$ & $\begin{array}{l}\text { Switches } \\
\text { turned on }\end{array}$ \\
\hline $1(+--)$ & $\mathrm{S} 6, S^{\prime} l, \mathrm{~S} 2$ & $1^{\prime}(+--)$ & $\mathrm{S} 6^{\prime}, \mathrm{S} 1^{\prime}, \mathrm{S} 2{ }^{\prime}$ \\
\hline $2(++-)$ & $\mathrm{S} 1, \mathrm{~s} 2, \mathrm{~S} 3$ & $2^{\prime}(++-1$ & $\mathrm{S}^{\prime}, \mathrm{S} 2^{\prime}, \mathrm{S}^{\prime}$ \\
\hline $3(-+-)$ & s2, s3, s4 & $3^{\prime}(-+-)$ & $\mathrm{S} 2^{\prime}, \mathrm{S} 3^{\prime}, \mathrm{S} 4^{\prime}$ \\
\hline $4(-++)$ & S3, s4, S5 & $4^{\prime}(-++)$ & $\mathrm{S} 3^{\prime}, \mathrm{S} 4^{\prime}, \mathrm{S}^{\prime}$ \\
\hline $5(--+)$ & S4, S5, S6 & $5^{\prime}(--+)$ & $\mathrm{S} 4^{\prime}, \mathrm{S}^{\prime}, \mathrm{S}^{\prime}$ \\
\hline $6(+-+)$ & S5, S6, S1 & $6^{\prime}(+-+)$ & $\mathrm{S}^{\prime}, \mathrm{S} 6^{\prime}, \mathrm{S} 1^{\prime}$ \\
\hline $7(+++)$ & s1, s3, s5 & $7(+++)$ & $\mathrm{S} 1^{\prime}, \mathrm{S} 3^{\prime}, \mathrm{S} 5^{\prime}$ \\
\hline $8(---)$ & $\mathrm{S} 2, \mathrm{~s} 4, \mathrm{~s} 6$ & $8^{\prime}(---)$ & $\mathrm{S} 2^{\prime}, \mathrm{S} 4^{\prime}, \mathrm{S} 6^{\prime}$ \\
\hline
\end{tabular}
determined. Fig. 2 depicts that these space-vectorcombina-

Table 1: Inverter states for individual inverters tions are distributed over 19 space-vector locations. similar to a conventional three-level inverter. All the space-vector combinations and the space-vector locations are shown in Fig. 2.

From Fig. 2, one may note the redundancy of the spacevector combinations for a given space-vector location. For example, when inverter- 2 attains a state of $1^{\prime}(+--)$, the points $B_{2}$ and $C_{2}$ are connected to the point $\mathbf{O}$ through the switches $\mathbf{S} 6^{\prime}$ and $\mathbf{S} 2^{\prime}$. The switches $\mathbf{S} 3^{\prime}$ and $\mathbf{S} 5^{\prime}$ block the DC-inputs for these two phases as the top and bottom switches in any given leg are switched complementarily in a two-level inverter. It may be noted that the common factor in the states of inverter-1, namely $8(---), 3(-+-)$, $4(-++)$ and $5(--+)$, is that in all these states, the point $\mathrm{A}_{\mathrm{I}}$ (DC-input to inverter-2) is connected to the DC-link voltage of $V_{d c} / 2$ (Fig. 1, Table 1). Consequently, the combinations 8-1', 3-1', 4-1', 5-1' correspond to the same location A. Additionally, the combination 1-7' also results in the same location.

In this paper, a space-vector modulation scheme is also presented. The switching sequences are devised to ensure a minimum switching frequency. There exist many switching sequences, but to demonstrate the working principle of the proposed topology, only a few combinations have been

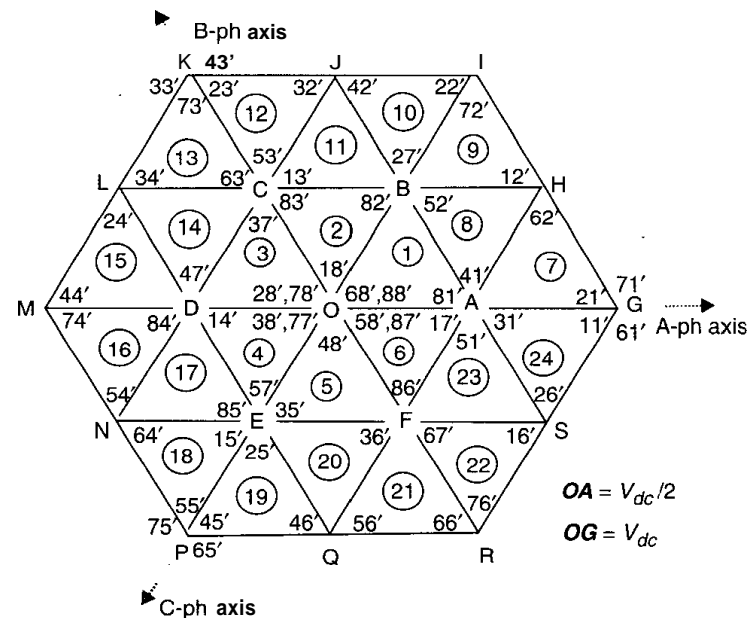

Fig. 2 The space-vector locations and combinations in the proposed circuit topology 
employed for a given location. The space-vector combinations used for the implementation of the spacevector modulation in the present work are presented in Fig. 3.

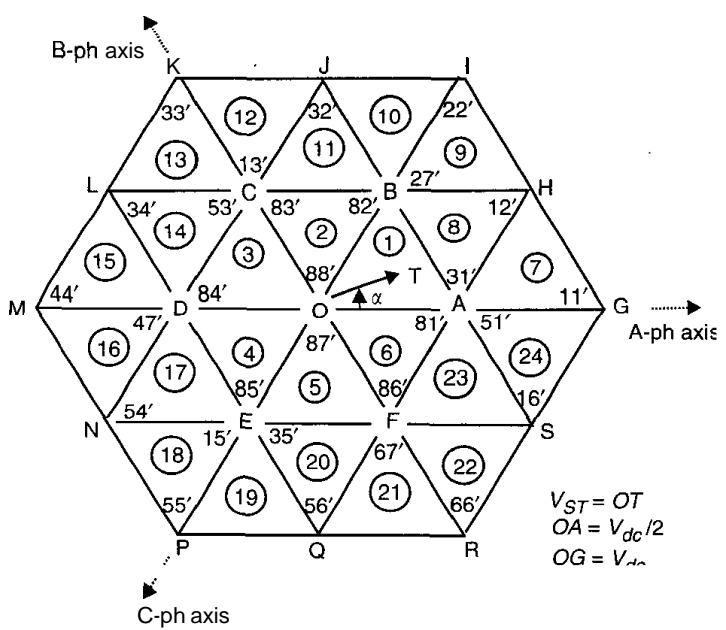

Fig. 3 The space-vector combinations used in the present work

The triplen harmonic currents are absent in this case as the neutral point $\mathrm{N}$ of the motor is not connected to the point $\mathbf{O}$. Hence all the triplen harmonic voltages appear across the points $\mathrm{O}$ and $\mathrm{N}$ (Fig. 1).

One advantage with the proposed topology is that, if the magnitude of the reference voltage space-vector is less than the radius of the maximum circle inscribed in the inner hexagon $\left(\left|v_{s r}\right|<0.433 V_{d c}\right)$, the tip of the reference voltage space-vector is always situated in the inner hexagon (Fig. 3). In this operating range, inverter- 1 is always clamped to the state $8(---)$ and inverter-2 alone is switched. Alternatively, inverter- 2 can be clamped to the state 7 $(+++)$ and inverter-1 could be switched. Consequently, in this operating range the switching losses are due entirely to the switching of one of these inverters and are expected to be lower than in the conventional inverter topology. The proposed power circuit can also be operated with a single DC power supply, with tapped capacitors, as in the case of a conventional neutral clamped inverter. In that case, the inverter cannot be operated as a two-level inverter in the range of lower modulation and a conventional threelevel PWM switching scheme is to be employed. This calls for the dynamic balancing of the capacitor voltages by exploiting the redundancy in the space-vector combinations, for a given location, similar to the schemes presented in $[7,8]$.

It may be noted that the fast recovery clamping diodes are not needed in the proposed circuit when compared to the conventional neutral clamped three-level inverter. However, the bottom bank switches of inverter-2 are to be rated for the full DC-bus voltage of $V_{d c}$, unlike the case of a conventional neutral clamped three-level inverter, in which all the switches are nominally rated for $V_{d c} / 2[1,4]$. For example, for the space-vector combination 1-l', the switches $\mathrm{S} 1$ and $\mathrm{Sl}^{\prime}$ are turned on in the A-phase legs of both the inverters. This makes $v_{A 2 O}=V_{d c}$. Consequently, the switch S4" must be rated for $V_{d c}$. The switches in the top bank of inverter-2 need not be rated for the full DC-link voltage of $V_{d c}$ because the top switch of any phase leg of inverter-2 blocks the DC-input voltage to inverter-2, when the corresponding bottom switch is turned on. Under these conditions, the bottom switches of the corresponding phases of inverter-] may be turned on so that the top switches of the corresponding phases in inverter-2 need to block only a voltage of $V_{d c} / 2$.

Considering the above limitations, it is envisaged that this circuit configuration is suitable for three-level inversion in low-voltage high-power applications (systems such as battery-operated electric vehicle drives) in view of the full DC-link voltage rating for the lower three power devices. One advantage of the proposed system is that the fast recovery neutral point clamping diodes are not needed.for the present power circuit. Also, from the engineering point of view, it is easy-to assemble such a system, as two existing two-level inverters can be retrofitted to realise this configuration. It should also be noted that the bus-bar design of a two-level inverter is considerably simpler than that of a three-level inverter. The proposed system can work as a conventional two-level inverter in low modulation indices, by clamping the upper inverter. This will reduce the inverter switching losses, when compared to a conventional three-level inverter, and so the overall efficiencv of the drive system can be improved.

\section{Switching strategy and PWM pattern generation}

\section{I Sub-hexagons, sectors and timing definitions}

The 64 voltage space-vector locations form the vertices of 24 equilateral triangles, which are referred to as sectors (Fig. 2). The equilateral triangles numbered 1 to 6 are referred to as 'inner sectors'. The equilateral triangles numbered $8,11,14,17,20$ and 23 are referred to as 'middle sectors'. The rest of the sectors (numbered 7, 9, 10, 12, 13, $15,16,18,19,21,22$ and 24) are referred to as 'outer sectors' (Fig. 3). Six adjacent sectors constitute a sub-hexagon. Six such sub-hexagons can be identified with their centres located at $\mathbf{A}, \mathrm{B}, \mathrm{C}, \mathrm{D}, \mathrm{E}$ and $\mathrm{F}$ respectively (Fig. 3). In addition there is one inner sub-hexagon with its center at $\mathbf{O}$ (Fig. 3). The reference voltage space-vector for the space-vector modulation is denoted as $\boldsymbol{v}_{\boldsymbol{s r}}$ and is resolved into two rectangular components $v_{\alpha}$ and $v_{\beta}\left(v_{s r}=v_{\alpha}+\mathrm{j} v_{\beta}\right)$, with the a-axis placed along the motor A-phase axis). The angle subtended by $\boldsymbol{v}_{s r}$ with the positive-A axis is denoted as a (Fig. 3). The voltages $v_{a}^{*}, v_{b}^{*}$ and $v_{c}^{*}$ denote the instantaneous reference phase voltages to realise $\boldsymbol{v}_{\mathrm{s} r}$ and are obtained by projecting the tip of $\boldsymbol{v}_{s r}$ onto the $\mathrm{A}, \mathrm{B}$ and $\mathrm{C}$ axes respectively (Fig. 4). The relationship between $v_{\alpha}$ and $v_{\beta}$ and $v_{a}^{*}, v_{b}^{*}$ and $v_{c}^{*}$ is given by the transformation:

$$
\left[\begin{array}{c}
v_{a}^{*} \\
v_{b}^{*} \\
v_{c}^{*}
\end{array}\right]=\frac{2}{3}\left[\begin{array}{cc}
1 & 0 \\
-1 / 2 & \sqrt{3} / 2 \\
-1 / 2 & \sqrt{3} / 2
\end{array}\right]\left[\begin{array}{c}
v_{\alpha} \\
v_{\beta}
\end{array}\right]
$$

The symbols $T_{1}$ and $T_{2}$, respectively, denote the time duration for which the active vectors along the trailing edge and the leading edge of a sector (in which the tip of the reference voltage space-vector is situated) are switched for the realisation of $\boldsymbol{v}_{s r}$. The symbol $T_{0}$ denotes the time duration for which a null vector is switched along with the active vectors to realise $\boldsymbol{v}_{\mathbf{s} \boldsymbol{r}}$. The sampling time period for space-vectormodulation is denoted as $T_{s}$ and is equal to the sum of the time periods $T_{1}, T_{2}$ and $T_{0}$. The inverter leg switching time periods are those during which the output phases of the inverter are connected to the positive terminal of the DC bus and are denoted as $T_{g a}, T_{g b}$ and $T_{g c}$ respectively for the phases $\mathbf{A}, \mathrm{B}$ and $\mathrm{C}$. In the conventional 


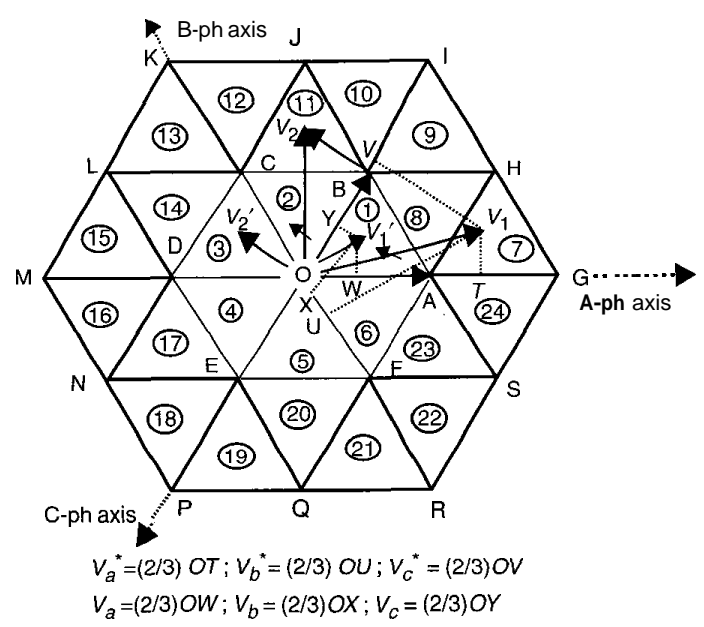

Fig. 4 Mapping of the outer sectors into the inner hexagon

system where a two-level inverter drives an induction motor, there exists an explicit relationship between these timings $\left(T_{g a}, T_{g b}\right.$ and $\left.T_{g c}\right)$ and the instantaneous reference phase voltages $\left(v_{a}^{*}, v_{b}^{*}\right.$ and $\left.v_{c}^{*}\right)$.

\subsection{Sector identification}

To implement the PWM pattern, the triangular sector in which the tip of the reference space-vector is situated is first identified and the sub-hexagon to which it belongs is found. The sector identification is based on level comparators along the $j a, j b, j c$ axes perpendicular to the a, b, c axes respectively [6]. The symbols $v_{j a}^{*}, v_{j b}^{*}$ and $v_{j c}^{*}$ denote the projections of $\boldsymbol{v}_{\boldsymbol{s r}}$ on to the $j a, j b$ and $j c$ axes respectively. It may be verified that the tip of $\boldsymbol{v}_{s \boldsymbol{r}}$, the reference voltage space-vector, is situated in sector 1 if

$$
v_{j a}^{*}<(\sqrt{3} / 4) V_{d c} ; v_{j b}^{*} \geq-(\sqrt{3} / 4) V_{d c} ; v_{j c}^{*}<(\sqrt{3} / 4) V_{d c}
$$

A similar procedure is adopted for the identification of all other sectors [6]. Table 2 summarises the conditions to be satisfied for all the sectors.
The PWM strategy adopted is based on whether the tip of the reference voltage space-vector is situated in the inner sectors (sectors 1 to 6, Fig. 3), in the middle sectors (sectors $8,11,14,17,20,23$, Fig. 3 ) or in the outer sectors. In the following sections the PWM strategies adopted for the above three cases are explained. Each cycle of the load phase-voltage is divided into 48 equal sub-intervals. Each sub-interval duration corresponds to the sampling interval, $T_{s}$. This division is maintained for the entire modulation range with $\mathrm{V} / \mathrm{f}$ control. The rated frequency of the induction motor corresponds to the maximum value of the magnitude of the reference voltage space-vector on the boundary of modulation. From Fig. 3, this boundary corresponds to the radius of the circle inscribed in the hexagon GTKMPR, and is equal to $0.866 V_{d c}$.

\subsection{Space-vector based PWM switching strategy for inner sectors}

If the tip of the reference voltage space-vector lies in the inner hexagon with centre at $\mathbf{O}$ (Fig. 3), a space-vector based scheme as suggested in [9] has been adopted. In this scheme [9], a space-vector based PWM strategy is proposed based on the instantaneous values of the reference voltages of a, b, c phases only. Ths method does not depend on the magnitude of the reference voltage spacevector and its relative angle with respect to the reference axis (a-axis placed along a phase axis). This space-vector PWM generation scheme is briefly outlined in the Appendix.

Ths method is extended for the proposed three-level inverter scheme (for PWM pattern generation in inner sectors 1 to 6$)$ by clamping inverter- 1 with state $8(---)$, while inverter- 2 alone is switched. Inverter- 2 is switched in such a way that there is only one switching for each subinterval of that sampling time period. For example, the inverter- 2 is switched through the states $8^{\prime}-1^{\prime}-2^{\prime}-7^{\prime}$, when $\alpha=0$. During the next sampling time period, inverter-', is switched with the reverse sequence, i.e. $7^{\prime}-2^{\prime}-1^{\prime}-8^{\prime}$, when $\alpha=7.5^{\circ}$. The actual switching time periods for each inverter leg are obtained in the same way as for the single inverter scheme [9]. Table 3 depicts a detailed description of the switching pattern along with the switching sequence. The switching sequence is indicated in brackets, adjacent to the switching pattern. For example the entry 88 '-81'-82'-87'

Table 2: Sector identification

\begin{tabular}{|c|c|c|c|c|c|c|c|c|}
\hline Sector & & $v_{j a}^{*}$ & $v_{j b}^{*}$ & $v_{j c}^{*}$ & Sector & $v_{j a}^{*}$ & $v_{j b}^{*}$ & $v_{j c}^{*}$ \\
\hline 1 & & $<\frac{\sqrt{3}}{4} V_{d c}$ & $\geq-\frac{\sqrt{3}}{4} V_{d c}$ & $<\frac{\sqrt{3}}{4} V_{d c}$ & 2 & $<\frac{\sqrt{3}}{4} V_{d c}$ & $\geq-\frac{\sqrt{3}}{4} V_{d c}$ & $\geq-\frac{\sqrt{3}}{4} V_{d c}$ \\
\hline 3 & & $<\frac{\sqrt{3}}{4} V_{d c}$ & $<\frac{\sqrt{3}}{4} V_{d c}$ & $\geq-\frac{\sqrt{3}}{4} V_{d c}$ & 4 & $\geq-\frac{\sqrt{3}}{4} V_{d c}$ & $<\frac{\sqrt{3}}{4} V_{d c}$ & $\geq-\frac{\sqrt{3}}{4} V_{d c}$ \\
\hline 5 & & $\geq-\frac{\sqrt{3}}{4} V_{d G}$ & $<\frac{\sqrt{3}}{4} V_{d c}$ & $<\frac{\sqrt{3}}{4} V_{d c}$ & 6 & $\geq-\frac{\sqrt{3}}{4} V_{d c}$ & $\geq-\frac{\sqrt{3}}{4} V_{d c}$ & $<\frac{\sqrt{3}}{4} V_{d c}$ \\
\hline 7 & & $<\frac{\sqrt{3}}{4} V_{d c}$ & $<-\frac{\sqrt{3}}{4} V_{d c}$ & $\geq \frac{\sqrt{3}}{4} V_{d c}$ & 8 & $<\frac{\sqrt{3}}{4} V_{d c}$ & $<-\frac{\sqrt{3}}{4} V_{d c}$ & $<-\frac{\sqrt{3}}{4} V_{d c}$ \\
\hline 9 & : & $\geq \frac{\sqrt{3}}{4} V_{d c}$ & $<-\frac{\sqrt{3}}{4} V_{d c}$ & $<\frac{\sqrt{3}}{4} V_{d c}$ & 10 & $\geq \frac{\sqrt{3}}{4} V_{d c}$ & $<-\frac{\sqrt{3}}{4} V_{d c}$ & $\geq-\frac{\sqrt{3}}{4} V_{d c}$ \\
\hline 11 & & $\geq \frac{\sqrt{3}}{4} V_{d c}$ & $\geq-\frac{\sqrt{3}}{4} V_{d c}$ & $\geq-\frac{\sqrt{3}}{4} V_{d c}$ & 12 & $\geq \frac{\sqrt{3}}{4} V_{d c}$ & $\geq-\frac{\sqrt{3}}{4} V_{d c}$ & $<-\frac{\sqrt{3}}{4} V_{o c}$ \\
\hline 13 & & $\geq \frac{\sqrt{3}}{4} V_{d c}$ & $<\frac{\sqrt{3}}{4} V_{d c}$ & $<-\frac{\sqrt{3}}{4} V_{d c}$ & 14 & $<\frac{\sqrt{3}}{4} V_{d c}$ & $<\frac{\sqrt{3}}{4} V_{d c}$ & $<-\frac{\sqrt{3}}{4} V_{d c}$ \\
\hline 15 & & $<\frac{\sqrt{3}}{4} V_{d c}$ & $\geq \frac{\sqrt{3}}{4} V_{d c}$ & $<-\frac{\sqrt{3}}{4} V_{d c}$ & 16 & $\geq-\frac{\sqrt{3}}{4} V_{d c}$ & $\geq \frac{\sqrt{3}}{4} V_{d c}$ & $<-\frac{\sqrt{3}}{4} V_{d c}$ \\
\hline 17 & & $\geq-\frac{\sqrt{3}}{4} V_{d c}$ & $\geq \frac{\sqrt{3}}{4} V_{d c}$ & $\geq-\frac{\sqrt{3}}{4} V_{d c}$ & 18 & $<-\frac{\sqrt{3}}{4} V_{d c}$ & $\geq \frac{\sqrt{3}}{4} V_{d c}$ & $\geq-\frac{\sqrt{3}}{4} V_{d c}$ \\
\hline 19 & & $<-\frac{\sqrt{3}}{4} V_{d c}$ & $\geq \frac{\sqrt{3}}{4} V_{d c}$ & $<\frac{\sqrt{3}}{4} V_{d c}$ & 20 & $<-\frac{\sqrt{3}}{4} V_{d c}$ & $<\frac{\sqrt{3}}{4} V_{d c}$ & $<\frac{\sqrt{3}}{4} V_{d c}$ \\
\hline 21 & & $<-\frac{\sqrt{3}}{4} V_{d c}$ & $<\frac{\sqrt{3}}{4} V_{d c}$ & $\geq \frac{\sqrt{3}}{4} V_{d c}$ & 22 & $<-\frac{\sqrt{3}}{4} V_{d c}$ & $\geq-\frac{\sqrt{3}}{4} V_{d c}$ & $\geq \frac{\sqrt{3}}{4} V_{d c}$ \\
\hline 23 & & $\geq-\frac{\sqrt{3}}{4} \dot{V}_{d c}$ & $\geq-\frac{\sqrt{3}}{4} V_{d c}$ & $\geq \frac{\sqrt{3}}{4} V_{d c}$ & 24 & $\geq-\frac{\sqrt{3}}{4} V_{d c}$ & $<-\frac{\sqrt{3}}{4} V_{d c}$ & $\geq \frac{\sqrt{3}}{4} V_{d c}$ \\
\hline
\end{tabular}


Table 3: Switching sequences in all sectors

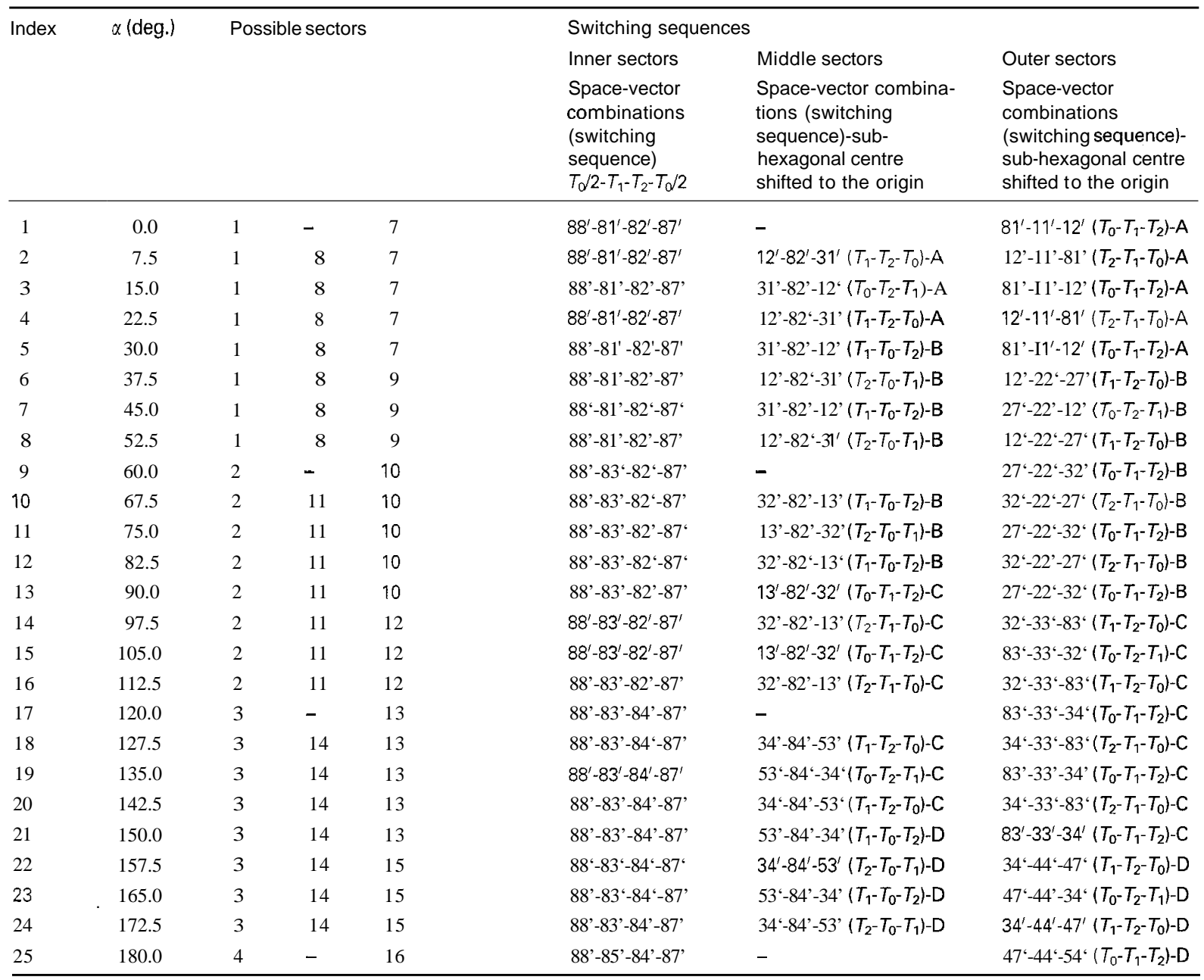

means that the combination $88^{\prime}$ is output for a duration of $T_{0} / 2$, the combinations $81^{\prime}$ and $82^{\prime}$ are output for durations of $T_{1}$ and $T_{2}$ respectively, and 87 ' is output for a duration of $T_{0} / 2$.

\subsection{Mapping the middle sectors and the outer sectors into the inner hexagon}

In Fig. 4, the reference voltage vectors $\boldsymbol{O} V_{1}$ and $\boldsymbol{O} \boldsymbol{V}_{2}$ at two different time instants are shown with their tips situated in sector 7 and sector 11, respectively. In sector 7 the vector $O V_{1}$ can be conceived to be the vector sum of two components $\boldsymbol{O A}$ and $\boldsymbol{A} \boldsymbol{V}_{1}$. The vector $\boldsymbol{O A}$ can readily be obtained from the appropriate space-vector combinations from the individual inverters (Fig. 3). The vector $\boldsymbol{A} \boldsymbol{V}_{\mathbf{1}}$ is not directly available from the space-vector combinations (Fig. 3) and hence is to be generated from the adjacent active switching vector locations $(\mathrm{A}, \mathrm{G}$ and $\mathrm{H})$ using voltsecond balance. The periods $T_{0}, T_{1}$ and $T_{2}$ for vector $\boldsymbol{A} \boldsymbol{V}_{1}$ in sector 7 , in a sampling time period $T_{s}$, can be determined by mapping the vector $A V_{1}$ to $O V_{1}^{\prime}$ by shifting the point A to $\mathbf{O}$. By shifting the point $\mathrm{A}$ to $\mathbf{O}$, the outer triangle $\mathbf{A G H}$ is mapped to an inner sector OAB (Fig. 4). It may be seen that the original reference vector $\boldsymbol{O} \boldsymbol{V}_{1}$ can be realised by using the same timings employed to realise $\boldsymbol{O} \boldsymbol{V}_{\mathbf{1}}{ }^{\prime}$. To realise $\boldsymbol{O} \boldsymbol{V}_{\mathbf{1}}$, the space-vectors located at $\mathbf{A}, \mathbf{G}$ and $\mathbf{H}$ are switched instead of the ones located at $\mathbf{O}, \mathrm{A}$ and $\mathrm{B}$. It is evident that this procedure is conceptually equivalent to producing $\mathbf{O} V_{1}^{\prime}$ and giving a vectored offset equal to $\boldsymbol{O A}$ to produce $\boldsymbol{O} \boldsymbol{V}_{\mathbf{1}}$.

Similarly, sector 11 can be mapped to the inner sector 3 by shifting the point $\mathrm{B}$ to $\mathrm{O}$. In this case, the vector $\boldsymbol{B} \boldsymbol{V}_{2}$ gets mapped to $\boldsymbol{O} \boldsymbol{V}_{\mathbf{2}}{ }^{\prime}$. Adopting this procedure, all outer sectors (7 to 24) may be mapped into the corresponding inner sectors. The generalised equations of transformation for the modified reference phase voltages when the sub-hexagonal centres $\mathrm{A}$ to $\mathrm{F}$ are shifted to $\mathbf{O}$ are given by:

$$
\begin{aligned}
& v_{a}=v_{a}^{*}-\left(V_{d c} / 3\right) \cos [(m-1) \cdot \pi / 3] \\
& v_{b}=v_{b}^{*}+\left(V_{d c} / 3\right) \cos [m \cdot \pi / 3] \\
& v_{c}=v_{c}^{*}+\left(V_{d c} / 3\right) \cos [(m-2) \cdot \pi / 3]
\end{aligned}
$$

In (6), $v_{a}^{*}, v_{b}^{*}$ and $v_{c}^{*}$ are the sampled phase values corresponding to the actual reference voltage space-vector $v_{s r}$ (Fig. 4). The voltages $v_{a}, v_{b}$ and $v_{c}$ correspond to the transformed reference voltage space-vector $\mathbf{O} V_{1}^{\prime}$ (Fig. 4). In (6), $m$ is an integer variable that takes values 1 to 6 corresponding to points $\mathrm{A}$ to $\mathrm{F}$ respectively (Fig. 3). The transformed reference phase voltages $v_{a}, v_{b}$ and $v_{c}$ are used to determine the inverter leg switching timings $-T_{g a}, T_{g b}$ and $T_{g c}$, by using the PWM generation scheme outlined in Section 3.3 and the Appendix. The timing periods $T_{0}, T_{1}$ 
and $\boldsymbol{T}_{2}$ to switch the space-vector combinations at the nearest vertices are then determined from the inverter leg switching timings $T_{g a}, T_{g b}$ and $\boldsymbol{T}_{r, r}$ as described in the following Sections for the middle sectors and the outer sectors.

\subsection{Space-vector based PWM switching strategy for middle sectors}

By shifting the centres of the sub-hexagons $\mathbf{A}$ to $\mathbf{F}$ to the point $\mathbf{O}$ using an appropriate coordinate transformation, the middle sectors (sectors numbered 8, 11, 14, 17, 20 and 23) are mapped to a corresponding inner sector (1 to 6). Once the mapped inner sector is identified, the switching periods for individual legs ( $T_{g a}, T_{g b}$ and $T_{g c}$ ) for both the inverters may be obtained using the procedure outlined in [9]. There exists an explicit relationship between the inverter leg switching timings ( $T_{g a}, T_{g b}$ and $T_{g c}$ ) and the space-vector switchng timings $\left(T_{0}, T_{1}\right.$ and $\left.\boldsymbol{T}_{2}\right)$ depending upon the sector of the inner hexagon in which the tip of the transformed reference space-vector $\boldsymbol{O} \boldsymbol{V}_{\mathbf{2}}^{\prime}$ is situated. Using these relationships the space-vector switching timings $T_{0}, T_{1}$ and $T_{2}$ can be determined from the inverter leg switching timings $T_{g a}, T_{g b}$ and $T_{g c}$. For example, if the tip of $\boldsymbol{O V _ { 2 }}$ is situated in sector 8 , the sub-hexagonal centre $\mathbf{A}$ is shifted to O if $0^{\prime \prime}<\alpha<30^{\prime \prime}$ mapping sector 8 to sector 2 in the inner hexagon. If $30^{\circ} \leq \alpha<60^{\circ}$, to ensure that the nearest subhexagonal centre is shifted to $\mathrm{O}$, the sub-hexagonalcentre $\mathrm{B}$ is shifted to $\mathbf{O}$ mapping sector 8 to sector 6 in the inner hexagon.

It may easily be verified that:

$$
\begin{aligned}
& T_{0}=2 T_{g c} ; T_{1}=T_{g a}-T_{g c} ; \\
& T_{2}=T_{g b}-T_{g a} \text { when sector } 8 \text { is mapped to sector } 2
\end{aligned}
$$
and

$$
\begin{aligned}
& T_{0}=2 T_{g b} ; T_{1}=T_{g c}-T_{g b} ; \\
& T_{2}=T_{g a}-T_{\text {”, }} \text { when sector } 8 \text { is mapped to sector } 6
\end{aligned}
$$

A similar procedure is adopted when the tip of $\boldsymbol{O} \boldsymbol{V}_{\mathbf{2}}$ is situated in the sectors $11,14,17,20$ and 23. Table4 summarises the relationships amongst $T_{1}, T_{2}$ and $T_{0}$ and $T_{g a}, T_{g b}$ and $\boldsymbol{T}_{r \prime}$, for all of the middle sectors. The space-vector combinations, the switching sequence and the sub-hexagonal centres transformed for each sampling time period for the outer sectors are depicted in Table 3 . It may be observed that $\boldsymbol{T}_{\mathbf{0}}$, the time duration for which a null vector is output, is not split into equal halves in this case.

\subsection{Space-vector based PWM switching strategy for outer sectors}

The procedure outlined for the middle sectors may be extended to the outer sectors. It may be noted that the orthogonal axes $j A, j B$ and $j C$ do not pass through the midst of the outer sectors, unlike the middle sectors (Fig. 3). Consequently, the sub-hexagonal centre to be shifted to the point $\mathbf{O}$ to map a given outer sector into a corresponding inner sector is always the same, unlike the case for a middle sector (Table 4). The relationships amongst the inverter leg switching timings $\left(T_{g a}, T_{g b}\right.$ and $\left.T_{g c}\right)$ and the space-vector switching timings $\left(T_{0}, T_{1}\right.$ and $\left.T_{2}\right)$ may be obtained from Table 4. The space-vector combinations, the switching sequence and the sub-hexagonal centres transformed for each sampling time period for the outer sectors are depicted in Table 3. In this case also, the time duration $\boldsymbol{T}_{\mathbf{0}}$ is not split into equal halves.

\subsection{Over-modulation}

When the reference vector is located outside the hexagon GIKMPR (Fig. 4), a modified reference voltage vector on the periphery of the hexagon having the same angle as the original reference vector is chosen [4]. The modified active vector switching times $T_{1}^{\prime}$ and $T_{2}^{\prime}$ during over-modulation with the modified reference voltage vector may be calculated simply by the following conditions:

$$
T_{1}^{\prime}+T_{2}^{\prime}=T_{s} \text { and } T_{1}^{\prime}: T_{2}^{\prime}=T_{1}: T_{2}
$$

Therefore

$$
\begin{aligned}
& T_{1}^{\prime}=\frac{T_{1}}{\left(T_{1}+T 2\right)} T_{s} \\
& T_{2}^{\prime}=\frac{T_{2}}{\left(T_{1}+T_{2}\right)} T_{s}
\end{aligned}
$$

\begin{tabular}{|c|c|c|c|c|c|c|}
\hline Range of $a$ & $\begin{array}{l}\text { Sector before } \\
\text { transformation }\end{array}$ & $\begin{array}{l}\text { Sub-hexagonal } \\
\text { centre shifted to } \\
\text { the point } O\end{array}$ & $\begin{array}{l}\text { Sector after } \\
\text { transformation }\end{array}$ & $T_{0} / 2$ & $T_{1}$ & $T_{2}$ \\
\hline $0^{\prime \prime} \leq \alpha<30 "$ & 7 & A & 2 & $T_{g c}$ & $T_{g a}-T_{g c}$ & $T_{g b}-T_{g a}$ \\
\hline $30 " \leq \alpha<60 "$ & 7 & B & 6 & $T_{g b}$ & $T_{g c}-T_{g b}$ & $T_{g a}-T_{g c}$ \\
\hline $60^{\prime \prime} \leq \alpha<90^{\circ}$ & 8 & B & 3 & $T_{g a}$ & $T_{g b}-T_{g c}$ & $T_{g c}-T_{g a}$ \\
\hline $90 " \leq \alpha<120 "$ & 8 & c & 1 & $T_{g c}$ & $T_{g a}-T_{g b}$ & $T_{g b}-T_{g c}$ \\
\hline $120^{\circ} \leq a<150^{\prime \prime}$ & 9 & C & 4 & $T_{g a}$ & $T_{g b}-T_{g a}$ & $T_{g c}-T_{g b}$ \\
\hline $150^{\circ} \leq \alpha<180^{\circ}$ & 9 & $\mathrm{D}$ & 2 & $T_{g c}$ & $T_{g a}-T_{g c}$ & $T_{g b}-T_{g a}$ \\
\hline $180 " \leq \alpha<210^{\prime \prime}$ & 10 & D & 5 & $T_{g b}$ & $T_{g c}-T_{g a}$ & $T_{g a}-T_{g b}$ \\
\hline $210 " \leq a<240 "$ & 10 & E & 3 & $T_{g a}$ & $T_{g b}-T_{g c}$ & $T_{g c}-T_{g a}$ \\
\hline $240^{\circ} \leq a<270^{\prime \prime}$ & 11 & $E$ & 6 & $T_{g b}$ & $T_{g c}-T_{g b}$ & $T_{g a}-T_{g c}$ \\
\hline $270 " \leq \alpha<300 "$ & 11 & $\mathbf{F}$ & 4 & $T_{g a}$ & $T_{g b}-T_{g a}$ & $T_{g c}-T_{g b}$ \\
\hline $300^{\prime \prime} \leq \alpha<330 "$ & 12 & $\mathrm{~F}$ & 1 & $T_{g c}$ & $T_{g a}-T_{g b}$ & $T_{g b}-T_{g c}$ \\
\hline $330 " \leq a<360 "$ & 12 & A & 5 & $T_{g b}$ & $T_{g c}-T_{g a}$ & $T_{g a}-T_{g b}$ \\
\hline
\end{tabular}

\section{Experimental results and discussion}

The proposed scheme is implemented for a $1 \mathrm{HP}$, threephase induction motor drive in open loop with $\mathrm{V} / \mathrm{f}$ control for different reference voltages covering the entire speed range. The gating signals for the proposed inverter drive

Table 4: Switching time calculation 
have been generated using a TMS 320F240 DS processor. A DC-link voltage of $300 \mathrm{~V}$ is used for experimentation $\left(V_{d c}=300 \mathrm{~V}\right)$.

The experimental results for $\left|v_{s r}\right|=0.4 V_{d c}$ are presented in Fig. 5. In this case, the tip of the reference voltage spacevector $\boldsymbol{v}_{\boldsymbol{s} \boldsymbol{r}}$ is confined to the inner sectors i.e. sectors 1 to 6 (Fig. 3).

The experimentally obtained waveforms of $v_{A 1 O}$ and the pole voltage $v_{A 2 O}$ for the-A phase legs are presented in Fig. $5 a$ (top and bottom traces respectively). As mentioned earlier, inverter-2 alone is switched in this case, while inverter-I is clamped to a state of $8(---)$. Thus the inverter system behaves in a similar way to a conventional two-level inverter with a DC-link voltage of $V_{d c} / 2$. The top trace of Fig. $5 a$ showing that $v_{A 1 O}=150 \mathrm{~V}$ $\left(V_{d c} / 2\right)$ confirms this fact. Fig. $5 b$ shows the waveform of $v_{A 2 N}$ (motor phase voltage) obtained experimentally.As one might expect, it is a familiar six-step waveform of a twolevel inverter. The motor phase current in this operating condition is shown in Fig. $5 c$. Fig. $5 d$ illustrates the normalised harmonic spectra of the voltages $-v_{A 2 O}$ and $v_{A 2 N}$ (top and bottom traces respectively). It may be noted that the triplen harmonic components are present in the spectrum of $v_{A 1 O}$, and are absent in that of $v_{A 2 O}$ All these components are dropped across the points $O$ and N (Fig. 1), as explained in Section 2.

The experimental results obtained when $\left|v_{s r}\right|=0.6 V_{d c}$ are presented in Fig. 6. In this case, the tip of the reference voltage space-vector is situated either in the middle sectors $(8,11,14,17,20$ and 23$)$ or in the outer sectors (Fig. 3). Fig. $6 a$ shows the experimentally obtained waveforms of $v_{A 1 O}$ and the pole voltage $v_{A 2 O}$ (top and bottom traces respectively). In this case, both the inverters are switched. Consequently, the DC-input for the phase-A leg of inverter$2\left(v_{A 1}\right)$ is switched amongst the voltages $V_{d c} / 2(150 \mathrm{~V})$ and $V_{d c}(300 \mathrm{~V})$, as is evident from Fig. $6 a$ (top trace). The bottom trace of Fig. $6 a$ shows the pole voltage $v_{A 2 O}$ in which all three levels, $-0, V_{d c} / 2(150 \mathrm{~V})$ and $V_{d c}(300 \mathrm{~V})$, are present, as expected from this topology. Fig. $6 b$ illustrates the experimentally obtained waveform of the voltage $-v_{A 2 N}$ (motor phase voltage). Fig. $6 c$ shows the motor phase current in this operating condition. Fig. $6 d$ shows the normalised harmonic spectra of voltages $v_{A 2 O}$ and $v_{A 2 N}$ (top and bottom traces respectively).

Figs. 7 and 8 show the experimental results when $\left|v_{s r}\right|=V_{d c}$ and corresponds to the case of over-modulation

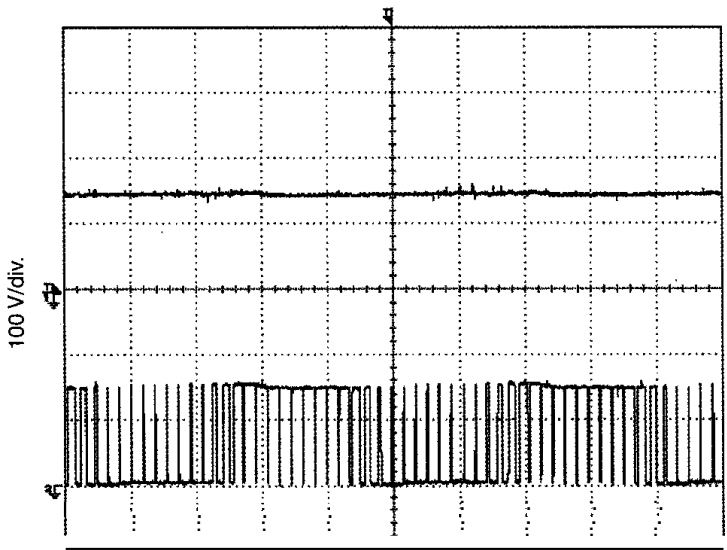

10 rnsldiv.

a

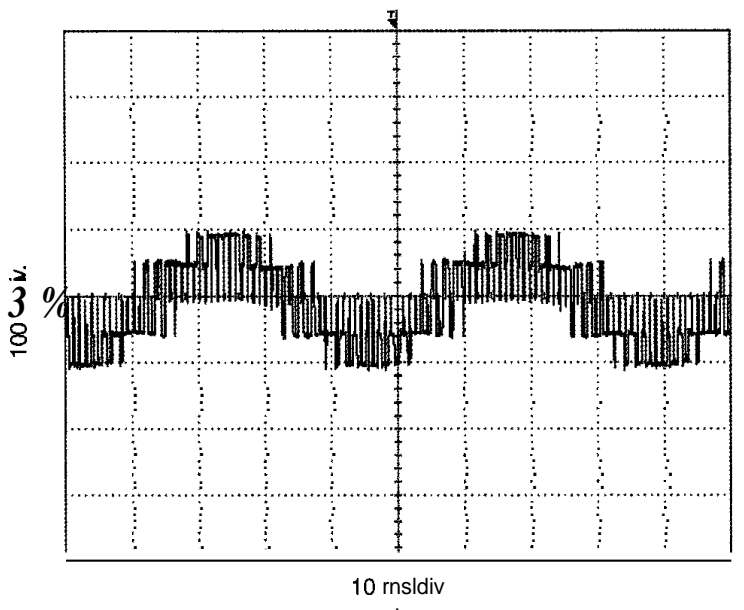

b

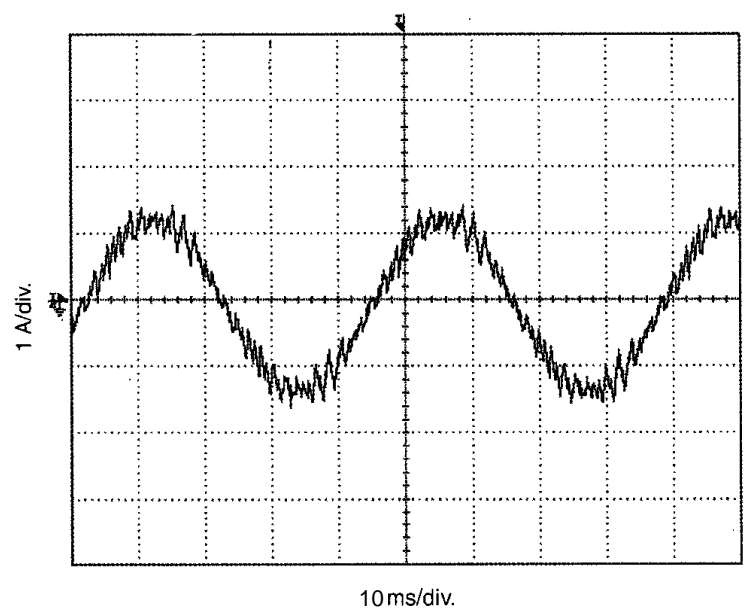

$c$
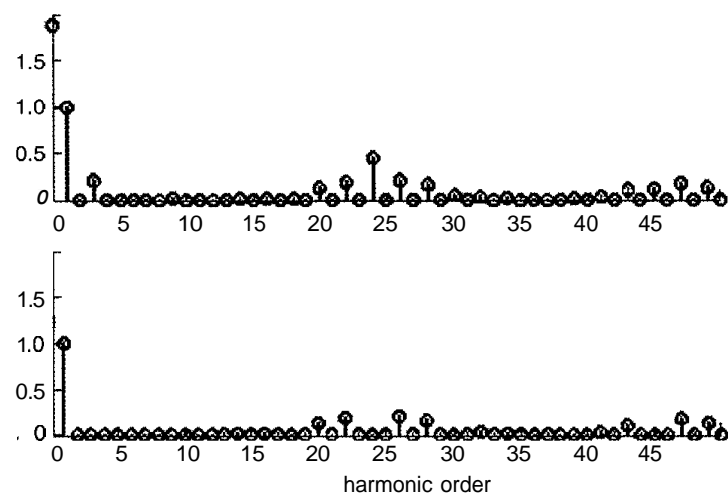

d

Fig. 5

a The experimental waveforms of pole voltages $v_{A 1 O}$ (top) and $v_{A 2 O}$ (bottom) for $\left|v_{s r}\right|=0.4 V_{d c}$

- $b$ The experimental waveform of motor phase-voltage $v_{A 2 N}$ for $\left|v_{s r}\right|=0.4 V_{d c}$

$c$ The motor phase current at no-load for $\left|V_{s r}\right|=0.4 V_{d c}$

$d$ The normatised harmonic spectra of $v_{A 2 O}$ (top) and $v_{A 2 N}$ (bottom) for $\left|V_{S T}\right|=0.4 V_{d c}$ 

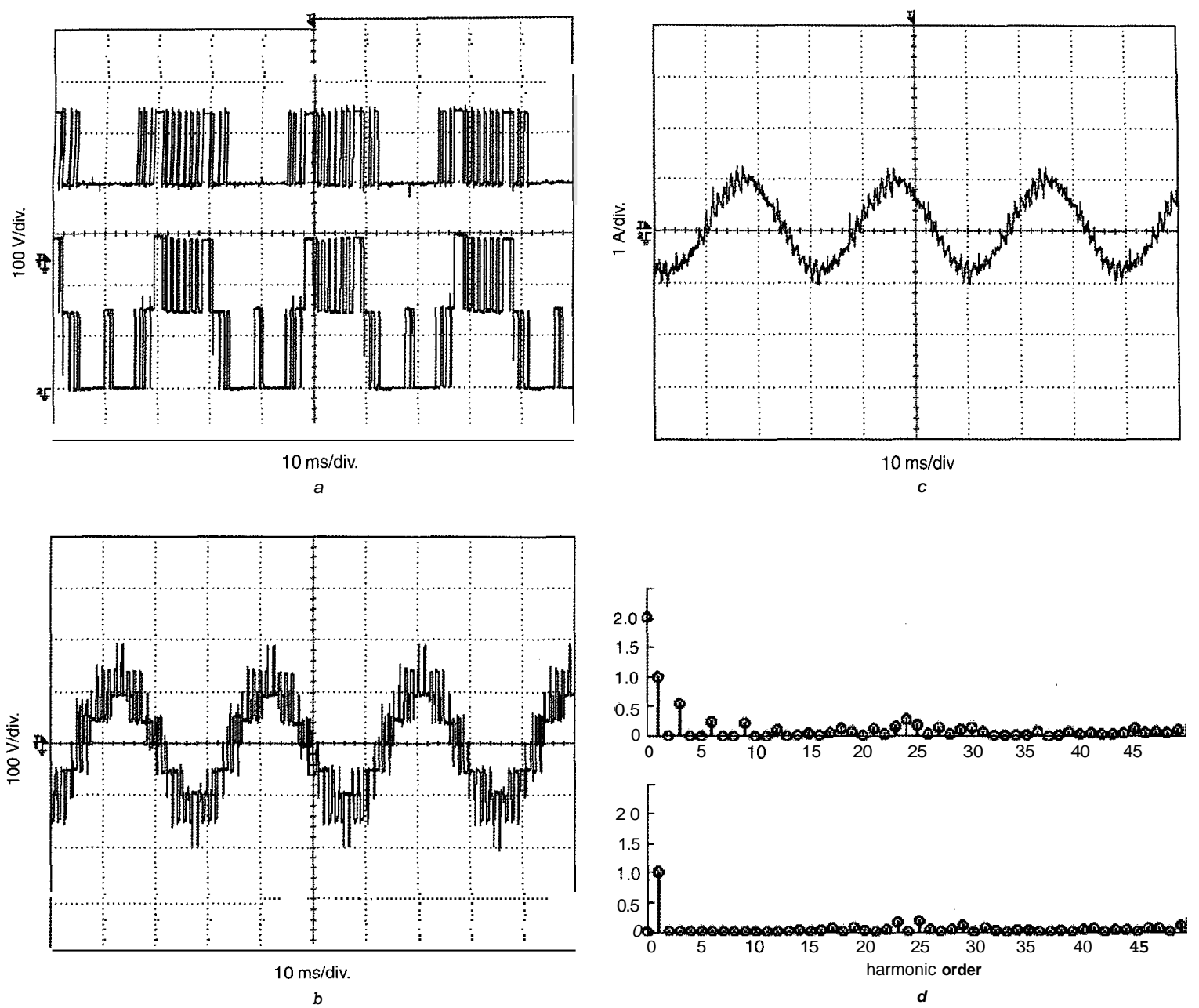

Fig. 6

a The experimental waveforms of pole voltages $v_{A 1 O}$ (top) and $v_{A 2 O}$ (bottom) for $\left|V_{s r}\right|=0.6 V_{d c}$

$b$ The expenmental waveform of motor phase-voltage $\mathrm{v}_{\mathrm{A} 2 \mathrm{~N}}$ for $\left|V_{s r}\right|=0.6 V_{d c}$

$c$ The motor phase current at no-load for $\left|V_{s}\right|=0.6 V_{d k}$

$\mathrm{d}$ The normalised harmonic spectra of $v_{A 2 O}$ (top) and $v_{A 2 N}$ (bottom) for $\left|V_{s r}\right|=0.6 V_{d c}$

as $\left|v_{s r}\right|>0.866 V_{d c}$ (Fig. 3). In this case, the tip of the reference voltage space-vector is forced to trace the hexagon GIKMPR (Fig. 3) as explained in Section 3.7. The experimental waveforms of the voltage $\boldsymbol{v}_{\boldsymbol{A} \boldsymbol{O}} \boldsymbol{O}$ and the pole voltage $v_{A 2 O}$ are presented in Fig. $7 a$ (top and bottom traces respectively). The experimental waveform of $v_{A 2 N}$ (motor phase voltage) is presented in Fig. $7 b$. Fig. $7 c$ shows the motor phase current in this operating condition. The normalised harmonic spectra of the voltages $v_{A 2 O}$ and $v_{A 2 N}$ (the motor phase voltage) are presented in Fig. 8 (top and bottom traces respectively).

Thus the three-level inverter proposed in this paper has been tested for the entire speed range using the $\mathrm{V} / \mathrm{f}$ control.

\section{Conclusions}

In the proposed scheme, two two-level inverters connected in cascade achieve three-level inversion. 64 voltage spacevector combinations are possible compared to the 27 combinations obtained in the conventional three-level inverter. As isolated DC power supplies are used to feed individual inverters, the DC-link capacitors carry only the ripple currents and not the load current. Thus, the voltage fluctuations of the neutral point are avoided. Two existing two-level inverters are retrofitted to realise three-level inversion. The neutral clamping diodes are not needed in this topology, when compared to a conventional NPC three-level inverter.

With two isolated DC link supplies, in the lower range of modulation (when $\left|v_{s r}\right|<\mathbf{0 . 4 3 3} V_{d c}$ ), one of the inverterscan be clamped to a zero inverter vector state and the other inverter can be switched as a two-level inverter reducing the switching losses, when compared to a conventional threelevel inverter. The proposed power circuit can also be used with a single DC link with tapped capacitors. In that case, the problem of neutral point balancing is to be addressed as in the case of a conventional three-level inverter, using the redundancy of the space vector combinations for a given location.

This configuration needs two isolated power supplies when compared to an H-bridge topology, which needs three isolated DC links. Three switches in the proposed scheme are to be rated to block the entire DC-bus voltage. 


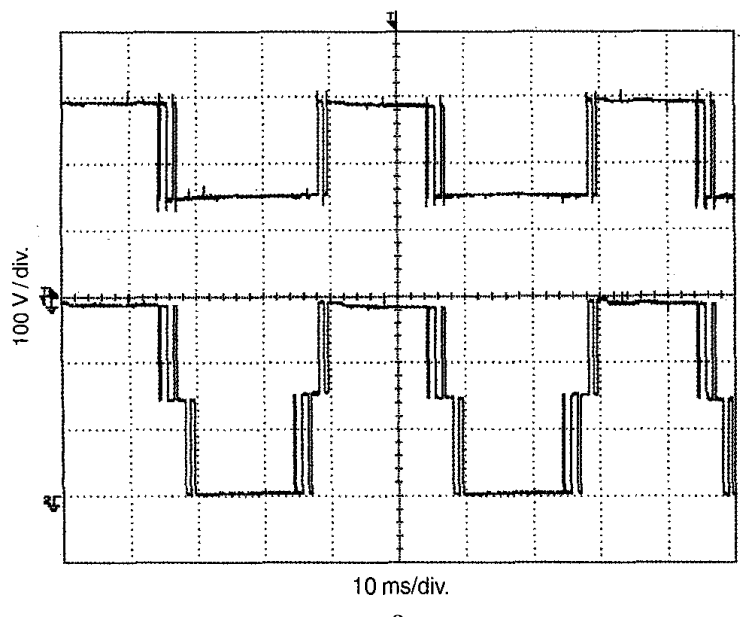

a
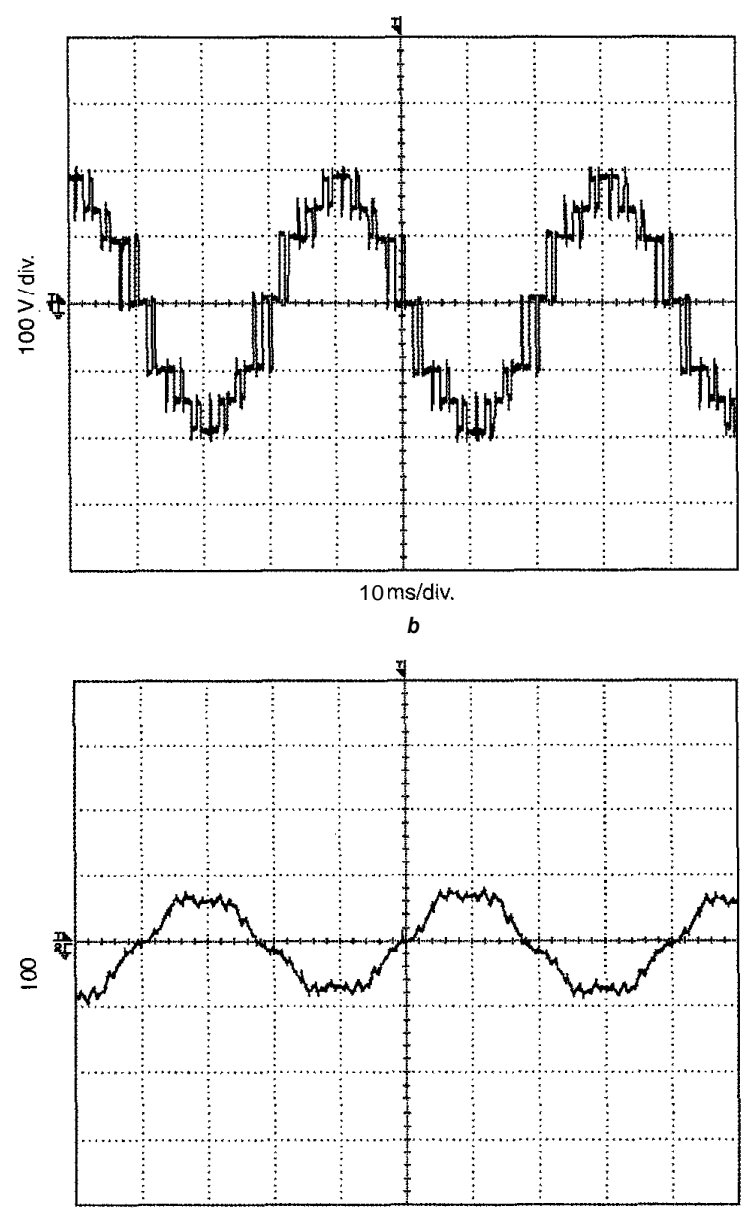

$10 \mathrm{~ms} / \mathrm{div}$

c

Fig. 7

a The expenmental waveforms of pole voltages $v_{A 1 O}$ (top) and $v_{A 2 O}$ (bottom) for $\left|V_{s r}\right|=V_{d c}$ (over-modulation)

$b$ The experimental waveform of motor phase-voltage $v_{A 2 N}$ for $\left|V_{s r}\right|=V_{d c}$ (over-modulation)

$c$ The motor phase current at no-load for $\left|V_{s r}\right|=V_{d k}$ (overmodulation)

The switching patterns are so devised that in each inverter only one leg is switched during a sub-interval of the sampling period $T$,.
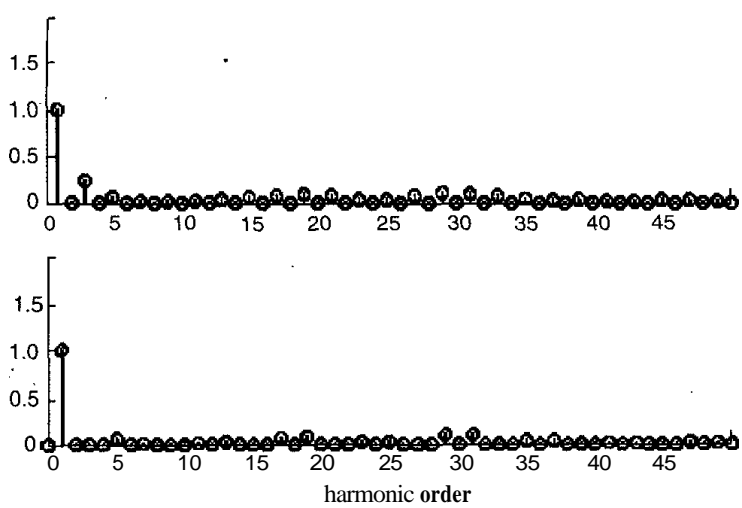

Fig. 8 The normalised harmonic spectra of $v_{A 2 O}$ (top) and $v_{A 2 N}$ (bottom) for $\left|V_{s r}\right|=\dot{V}_{d c}$ (over-modulation)

\section{References}

1 NABAE, A., TAKAHASHI, I., and AGAKI, H.: 'A new neutralpoint-clamped PWM inverter', IEEE Trans Ind Appl, 1981, 17, pp. 518-523

2 MANJREKAR, M.D., and LIPO, T.A.: 'A Hybrid Multilevel Inverter Topology for Drive Applications'. Proceedings of 13th Annual Applied electronics Conference (APEC), California, 15-19 February 1998, pp. 523-529

3 RUFER, A., VEENSTRA, M., and GOPAKUMAR, K.: 'Asymmetric multilevel converter for high resolution voltage phasor metric multilevel converter for high resolution voltage phasor electronics and applications (EPE), Lausanne, 13-16 September 1999, pp. P1-P10

4 SUH, B.-S., and HYUN, D.-S.: 'A New N-level High Voltage Inversion System', IEEE Trans. Ind. Electron., 1997, 44,(1), pp. 107115

5 STEMMLER, H., and GUGGENBACH, P.: 'Configurationsof high power voltage source inverter drives'. Proceedings of 5th European Conference on Power electronics and applications (EPE), Brighton, Conference on Power electronics and applications (EPE), Brighton,

6 SHIVAKUMAR, E.G., GOPAKUMAR, K., and RANGANATHAN, V.T.: 'Space vector PWM control of dual inverter fed open-end winding induction motor drive'. Proceedings of 16th Annual Applied electronics Conference (APEC), California, 4-8 March 2001, pp. 394-404

7 LEE, Y.-H., SUH, B.-S., and HYUN, D.-S.: 'A novel PWM scheme for a three level voltage source inverter with GTO thyristors', JEEE Trans. Ind. Appl., 1996, 32, (2)

8 VON JOUANNE, A., DAI, S., and ZHANG, H.: 'A simple method for balancing the DC link voltage of three level inverters'. Proceedings of 32nd Annual Power electronics Specialists Conference (PESC), Vancouver, Canada, 17-21 June 2001, pp. 1341-1345

9 KIM, J.-S., and SUL, S.-K.: 'A Novel Voltage Modulation Technique of the Space Vector PWM'. International Power Engineering Conference, IPEC, Yokohama, 3-7 April 1995,pp. 742-747

\section{Appendix}

In sector 1 , the switching periods for the active vectors $T_{1}$ and $T_{2}$ may be expressed in terms of the instantaneous values of the reference phase voltages $v_{a}^{*}, v_{b}^{*}$ and $v_{c}^{*}$ as [9]:

$$
T_{1}=\frac{T_{s}\left(v_{a}^{*}-v_{b}^{*}\right)}{V_{d c}} ; T_{2}=\frac{T_{s}\left(v_{b}^{*}-v_{c}^{*}\right)}{V_{d c}}
$$

From (11), the switching time periods proportional to the instantaneous values of the reference phase voltages, termed imaginary switching times, are defined as [9]:

$$
T_{a s} \equiv\left(\frac{T_{s}}{V_{d c}}\right) v_{a}^{*} ; T_{b s} \equiv\left(\frac{T_{s}}{V_{d c}}\right) v_{b}^{*} ; T_{c s} \equiv\left(\frac{T_{s}}{V_{d c}}\right) v_{c}^{*}
$$

From (11) and (12) the active vector switching times $T_{1}$ and $T_{2}$ in sector 1 may be expressed as:

$$
T_{1}=T_{a s}-T_{b s} ; T_{2}=T_{b s}-T_{c s}
$$

Extending this procedure for the other sectors, the active vector switching times $T_{1}$ and $T_{2}$ for the respective sectors 
may be expressed in terms of the imaginary switching times $T, T_{b s}$ and $T_{c s}$ for a particular sampling interval.

The effective time $T_{\text {eff }}$ is the time during which the active vectors are switched in a sector and is given by $\left(T_{1}+T_{2}\right)$. This may be determined as the difference between the maximum and minimum values among $T_{n} \quad T_{b s}$ and $T_{c s}$. The time duration $T_{0}$, the time for which a zero vector is applied, may be obtained from $T_{1}$ and $T_{2}$ as:

$$
T_{0}=T_{s}-T_{e f f}
$$

where

$$
\begin{aligned}
T_{e f f} & =\max \left\{T_{a s}, T_{b s}, T_{c s}\right\}-\min \left\{T_{a s}, T_{b s}, T_{c s}\right\} \\
& =T_{\max }-T_{\min }
\end{aligned}
$$

The offset time $T_{\text {offset }}$ required to distribute the zero voltage symmetrically during one sampling period is given by [9]:

$$
T_{\text {offset }}=\frac{T_{0}}{2}-T_{\min }
$$

The actual switching times for each inverter leg $T_{g a}, T_{g b}$ and $T_{g c}$ can be obtained by the time shifting operation as follows:

$$
\begin{aligned}
& T_{g a}=T_{a s}+T_{o f f s e t} ; T_{g b}=T_{b s}+T_{o f f s e t} \\
& T_{g c}=T_{c s}+T_{o f f s e t}
\end{aligned}
$$

